Mariano Latorre

\title{
La miel del rico
}

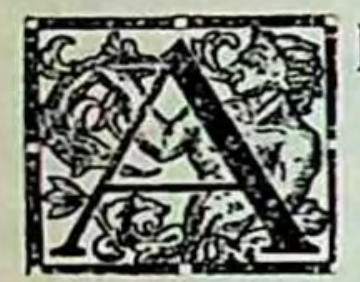

LBA fresca entre los altos robles. Chillar de diucas en los matorrales y maquis; chillar interminable, cada vez más nutrido, más penetrante a medida que la claridad se acerca; balido de ovejas en el corral, a espaldas del rancho. La vieja, que duerme en el corredor, grita a su nieto:

-Chilo, que ya va a rayar el sol.

De entre unos cueros sucios, surge un puñado de harapos restregándose los ojos; coge, primer acto de su aderezo, un sombrerillo verdoso, roto en los bordes, que mete en su pelambre negra asomada en forma de dos cuernos por debajo de las orejas; el pantalón tiene tal conjunto de parches y trozos descosidos que da la impresión de hallarse crespo.

La voz de la abuela, una viejecita delgada de ojos rojizos y palabra temblorosa, recomienda al nieto:

- No ejís las ovejas solas como ayer, pa que se junten con las de Cheuqueán.

Güeno, acepta bostezando el muchacho. 
-No le busquí cachureo al hijo de Cheuqueán; si no, le igo a tu paire.

Pero el muchacho no contesta; ha quitado ya las tablas que forman la puerta del corral; y las ovejas, atropellándose, balando en todos los tonos, se precipitan por la angosta entrada y corren un trecho hacia el prado, se desparraman entre los inmensos troncos rojizos que no ha alcanzado el fuego destructor y que aun corona la verde pompa del follaje.

En ese instante el sol dora la cima de los árboles: el alba se ahoga en la clara luz: resuena, sedoso, el arrullo de las torcazas en las ramas; y en el aire, de increible pureza, el grito de los chucaos se prolonga en extrañas sonoridades.

El muchacho arrea el rebaño heterogéneo, donde se mezclan las flacas ovejas indianas con el volumen hinchado de las razas extranjeras: algunas cojean lastimosamente, las pezuñas torcidas por la epizootia; otras tosen como viejas acatarradas; los lechones balan doloridos a la zaga de las madres; el muchacho lleva la honda recogida en el puño; al menor ruido de alas entre los matorrales, los cordeles se alargarán cobrando una vida repentina, y la honda se tornará en sus manos en una arina mortífera; pobre del cernícalo o torcaza que, descuidado, se ponga al alcance de sus ojos.

Las ovejas han amanecido andariegas; el pasto es tan mísero a causa de la seca, que sus dientes no alcanzan a cortarlo; el rebaño avanza, paso a paso. hacia los claros de la selva donde verdea el pasto al abrigo de la sombra; alli el bosque se hace compacto, 
los robles se yerguen corpulentos, bañado el rumor de su copa en la quietud azul y luminosa del aire.

El muchacho recuerda aquí súbitamente: entre esos árboles está el pellín donde descubrió, hace algunos días, una colmena silvestre.

Siente el deseo de ir a inspeccionar el árbol; sin remordimiento, abandona las ovejas y las deja entregadas a su suerte; se interna en el bosque siguiendo la primitiva cerca de palos botados unos al lado de los otros, aun prendidos a sus troncos por rojas astillas resecas; allí está, aislado en un claro, el palo con su aéreo colmenar en la cúspide.

No es un árbol muerto; pero la llama alcanzó a morderlo en un roce no lejano; conserva su costra rojiza de pellín; uno de sus ganchos se alarga como un brazo que pidiera limosna y en él verdea un racimo de hojas primaverales, último vestigio de savia en el gajo seco: alli, en el punto de unión del gancho y del tronco, se ve el agujero negro por donde entran y salen las abejas incesantemente.

El chiquillo lo mira con placer, sus labios chasquean golosos al recuerdo de la miel; sus tripas gorgoritean, no satisfechas con el mísero ulpo y el desabrido plato de arvejas de la temporada. Espera sólo que su padre llegue de una cosecha en tierra de indios para comunicarle la nueva.

El roble está en la hijuela del rico; y aunque-- según la tradicional costumbre del mediero - la mitad es del patrón, el muchacho sueña con el panal entero. Piensa que su padre será de su opinión.

Ya el sol está alto; y empieza a calentar. Verano 
único, sin lluvias; desde la mañana un pesado sopor gravita sobre la campiña; los pájaros se ocultan en el follaje; sólo el tiuque vuela pesadamente de un árbol a otro; o algún cernícalo, en la punta de un palo seco, avizora su presa sin temor al sol canicular.

Chilo se decide a abandonar su tesoro. Mira hacia arriba, hacia la boca negra como una úlcera donde el zumbido característico rodea la inmóvil serenidad del viejo pellín.

Se pierde como un zorro entre los renuevos de maquis que retoñan en torno a los troncos carbonizados con lecunda pujanza; el rebaño ha pasado ya la puerta de trancas y corre hacia el descampado donde pastan las ovejas del indio Cheuqueán.

El muchacho empieza a rodearlas; más bien a jugar con su honda que despide proyectiles a tontas y a locas, a dar gritos que se repiten a través de umbrías y quebradas con misteriosa repercusión; el rebaño, a cada proyectil, a cada grito, toma una dirección distinta, se alarga o se ensancha como una nube, modelada por el capricho del viento.

Luego descansa. Ha cogido una rama de maqui acribillada con la mostacilla oscura y lustrosa de su fruta; hábilmente, como un chino, se traga una tras otra las sabrosas pildoras y aparecen unos enormes boquerones violados que agrandan cómicamente su boca como la de un payaso; se ha encaramado en una tranquilla; allí se confunde casi con la madera resecada por el viento y el sol.

De pronto su cabecita va girando hacia los robles. buenos gigantes alineados pacíficamente unos al lado 
de los otros: detrás de los pellines se divisa el techo de totora de un rancho; de allí ha salido con un hacha al hombro, el hijo de Cheuqueán: Chilo lo ve avanzar por entre los matorrales. Debe ir a rozar, piensa el ovejero: pero luego se queda estupefacto. Cheuqueán avanza hacia la hijuela del rico; lo ve azomarse por entre unos árboles y luego perderse entre los maquis. Un segundo le preocupa el camino de Cheuqueán; pero se trainquiliza; los pequeños puntos negros que salpican la rama empiezan a desaparecer rápidamente en la boca de Chilo; sigue con la vista el vuelo de unas bandurrias cuya corneta característica resuena en el bosque; luego se deja deslizar por la cerca al suelo.

Se vuelve de pronto sorprendido: en el silencio limpido de la selva se oye el acompasado, sonoro golpe del hacha que derriba un árbol. Chilo se representa rápidamente el origen de esos hâchazos; su padre no está en la hijuela; nadie ha venido de las casas; luego es Cheuqueán que ha encontrado el panal y lo va a cosechar.

A este Cheuqueán lo tiene Chilo incrustado en el cerebro. Toda su espontánea agresividad de hombre primitivo la concentra en Cheuqueán. Descubre siempre panales y nidos en los árboles; tiene una potranca de año que ha comenzado a amansar; es un hombre de suerte, piensa Chilo con envidia.

Corre ágilmente entre los renuevos de maqui; salta como un cabro sobre los trozos cortados por la siera para cercas y tablones, en dirección al panal. Al llegar, se asoma precavidamente entre las ramas. 
El indio golpea el tronco del roble; el astil del hacha con su espejeante uña de acero es como una prolongación de su brazo de bronce: cae sobre el pellín y las astillas rojas, húmedas, perfumadas, saltan como gotas de sangre; la ancha herida se abre cada vez más hacia el corazón del roble; el árbol se estremece a cada golpe del hacha; gotas de sudor resbalan por el lustre oscuro de su piel; $\sin$ embargo, no desmaya.

Chilo permanece un segundo sin aliento, emocionado; no puede articular una palabra, en espera de una tregua del hacha para hablar; por fin, su voz entrecortada por la cólera le grita:

- ¿Quién ti ha dao permiso pa voltiar palos en l'hijuela el rico?

El indio detiene asustado su tarea; reina durante un minuto, un silencio impresionante; luego se oye pesado, persistente, el zumbar de las abejas en lo alto del roble, como una alada aureola rumoreante, ajena a lo que pasa al pie de su torre de marfil.

La sutil humareda de mil roces, en cada rincón de la selva, disemina en el aire su polvillo gris; envuelve los árboles en un tono opaco, que hace más bochornoso y pesado el calor; es como si la nota aguda de la mañana-rumor de ramajes, correr de aguas en la hojarasca, piar de pájaros-sonase en una sorda nota ahogada.

El indio, chorreante de sudor la ancha cara cobriza. el torzo desnudo, los brazos vigorosos en el astil del hacha, parece, por su inmovilidad, una estatua modela- 
da en pleno campo y con la barnizada arcilla que dormita en la margen de los esteros.

Su cara ancha, no muestra, sin embargo, haber experimentado emoción alguna; por último, en su castellano exótico, atragantado, tartamudea:

- Panal yo vide primero.

Es un muchacho de veinte años-ojotas sucias, pantalones tan raídos como los de Chilo-es negra como un ala de tordo la pelambre tiesa que invade la frente hasta los ojos pequeños y amortiguados. Chilo, sin embargo, créese de una raza superior; trata al indio ccmo el patrón lo trata a él; su voz ordena con insolencia:

- No sabis que l'hijuela es de on Belmar?

Cheuqueán se escupe tranquilamente las manos y sin hacer caso de las palabras del niño continúa su hacheo interrumpido.

La voz de Chilo se eleva sobre los golpes, colérica y amenazadora.

- Naide tiene permiso pa voltiar palos en las hijuelas ajenas.

El indio continúa impasible su tarea; su brazo se eleva en un amplio semi-círculo y resbala por el astil lustroso; reciamente, el hacha muerde la húmeda carne del pellin, que se deshace en rojas salpicaduras.

Chilo pierde los estribos; los insultos vuelan como pedruscos desde la cerca al roble, entremezclados con palabras mapuches que no impresionan al impertérrito hachero de la selva; por último empieza a lapidarlo con su onda, hasta que una piedra golpea rudamente el pechazo descubierto. El indio abandona el hacha y persigue al muchacho por entre los troncos y los maquis; el 
chiquillo le toma distancia en una rápida carrera hacia su puebla; se detiene y observa; el indio no ha seguido la persecución. Una sonrisa abre aún más la boca de Chilo; sus amenazas han tenido efecto. Vuelve nuevamente con toda clase de precauciones hacia el roble donde está el tesoro; no se oye ruido alguno que delate la presencia de una persona: chirrían las chicharras en el aire cálido; y al callarse su chirrido molesto, se oye el bordón de los moscardones que visitan las humildes corolas silvestres; tropieza con las ovejas en el trayecto; las ve, sin inquietarse, mordisquear el nocivo renuevo del lingue; se detiene de pronto junto a una mata de maqui; resuenan otra vez los hachazos en el bosque, y la escena vuelve a repetirse; el muchacho insulta desde la cerca y el indio continúa hachando el árbol.

Chilo añora a su padre que habría ahuyentado a Cheuqueán con un solo grito: el indio debe saber que no está en su puebla, piensa Chilo; por eso abusa; sus puños se aprietan con rabia impotente; un anhelo invencible angustia su cuerpecillo semidesnudo; pero de improviso se le ocurre una idea salvadora; con voz ronca amenaza, al mismo tiempo que baja la cerca en actitud decidida:

- Voy a avisarle al patrón al lago...

El indio debió ver en el muchacho la decisión de cumplir su amenaza; suelta el hacha y rápidamente se acerca a Chilo.

Su voz opaca, a la que intenta dar un tono amistoso. deja caer estas palabras tartamudeantes:

Vos, Chilo, entonces vení más mejor.

Chilo vuelve hasta la cerca; allí, ambos se observan 
un segundo; y se establece la entente cordial, con estas palabras del indio:

- Mitá miel rico pa vos.

Del otro lado de la cerca, como la firma de un contrato, el muchacho mete su onda en el bolsillo y acepta: Güeno.

Pasa la cerca; y sigue al indio hacia el árbol. Los hachazos comienzan de nuevo; el ángulo de la abertura ocupa ya casi la mitad del grueso tronco; en ese instante el indio detiene su trabajo y mira al árbol de soslayo: continúa hachando acompasadamente. Chilo aspira con delicia la acre humedad de la madera recién descubierta; es en él una sensación habitual, pues los árboles caídos marcan el paso del hombre en la selva; de pronto el hacha se hunde en las astillas endebles descubriendo la médula podrida del pellín.

Chilo observa pretensiosamente:

- Toos los pellines tan vanos.

$\mathrm{Y}$ luego, como ha visto hacer a su padre cuando cosecha la miel silvestre, aplica el oído al hueco: el agitado zumbido de alas de las abejas ventiladoras de la colmena, se oye como el ruido de un arroyo lejano; el muchacho cree sentir en sus narices la olorosa fragancia de la miel.

Cheuqueán empieza a golpear por el otro lado; y ya no se detiene, hasta que el sólido mástil parece estremecerse, apenas sujeto a su base por un milagro de su equilibrio secular, por la sabia disposición de las fibras en su ascenso hacia el aire azul.

Los dos quedan a la expectativa en las cercanías del árbol; el pellín se inclina ligeramente hacia la cerca; y 
el indio, con ojo certero, ha visto ya al árbol en el suelo y la boca del panal entre los renuevos del maqui. Ambos inspeccionan atentos, los ojos fijos en el revuelo de las obreras que llegan desde el campo o salen disparadas, ajenas a la tragedia cercana; el viento parece rozar súbitamente al árbol con su ala invisible; crujen quejumbrosamente las esquirlas que aun lo sujetan al tronco; y el pellín, perdiendo para siempre su airosa vertical de siglos, azota la tierra con estruendo; el gajo implorante queda hacia arriba, esta vez como un brazo que pide auxilio.

$\mathrm{El}$ indıo coge un balde que tiene oculto entre la yerba; y se precipita hacia el extremo; Chilo lo sigue con el júbilo pintado en sus pupilas zahareñas; pero no pueden acercarse. Es furioso el zumbar de la colmena en torno de la abertura por donde se escurre un chorro de miel espesa, descentrada de sus celdillas a causa de la violencia del golpe.

$\mathrm{El}$ indio se detiene precavidamente; y observa:

- Tan bravas a la siesta.

Chilo recuerda lo que su padre hace en estas ocasiones:

- Hay que atontarlas con el humo.

Recogen astillas secas y ramitas que el indio amontona en las cercanías del panal; Chilo no le pierde pisada; pero las abejas, como si estuviesen conscientes del peligro que corre su rubia vivienda, se precipitan sobre ellos como pequeñas y venenosas balas aladas; el indio las aparta con los brazos; pero su espalda está cubierta de aguijones; enciende las astillas, sin embargo; el humo comienza a caminar por el tronco; las 
abejas, asfixiadas, huyen en todas direcciones, golpeándose en las ramas y en los troncos; clavando su aguijón donde quiera que tropiezan, dispuestas a no sobrevivir a la ruina de su colmena y de su reina.

Chilo huye amedrentado hacia los maquis; donde se tiende en el suelo; ha sentido en el cuello y entre los cabellos, la aguja de varias picaduras.

Al levantarse de nuevo, ve al indio que saca un trozo amarillento de cera vieja.

- Na miel, murmura arrojándole el despojo; abeja nueva.

Pero Chilo no es lerdo en psicología mapuche; hay que enterarse por sí mismo; y valientemente esta vez, avanza hasta la abertura donde muchas abejas, embadurnadas las alas en su propia miel, hierven como las moscas en una herida descompuesta; sin miedo, hunde su mano en el agujero y saca una paleta chorreante de miel dorada, maravillosa destilación de sol, de savias y aire silvestre; la lengua ávida chupa el néctar delicioso, que resbala por la garganta hacia el estómago: luego. hecha una pelota, arroja la cera contra un tronco donde queda adherida; la escena se repite varias veces; introduce una y otra vez su mano en el agujero; y durante una hora, el indio y el niño, envueltos en el zumbido ahogado de las abejas agonizantes, chupan la miel del rico hasta quedar tendidos en el pasto, repletos, soñolientos, como bestias hartas, olvidados de todo.

Las horas de la selva resbalan por sus caras pringadas y sus vientres deformemente hinchados. limpidas. luminosas, imperturbables. 